\title{
Estilos de aprendizaje y el trabajo en el aula
}

Yanid Acosta González / Rómulo Bernal Acevedo

\section{Si lo escucho, lo olvido; si lo veo, \\ lo recuerdo; si lo escucho, lo veo y lo practico, lo aprendo para siempre.}

Confucio

\section{Introducción}

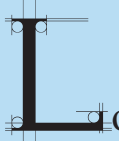

os psicólogos atribuyen el concepto de estilo de aprendizaje al comportamiento de cada persona en el proceso de aprendizaje y a cómo aquélla utiliza su propio método o estrategia para aprender. Por lo tanto, es uno de los pilares fundamentales para desarrollar el aprender a conocer (Delors, 1999: 17).

Según lo mencionan Felder y Silverman (citados por Durán y Costaguta, 2007: 1-10), los alumnos aprenden y procesan la información de diferente manera. Esto ayuda al alumno a desarrollar distintas habilidades sociales, cognitivas y de razonamiento, como son discutir, explicar sus ideas, comunicarlas, y ser responsable en las actividades colaborativas en la formación de grupos.

En este contexto, en la Universidad Tecnológica de Aguascalientes se aplicó un test de estilos de aprendizaje a un grupo de diecisiete alumnos del nivel técnico superior universitario del tercer cuatrimestre de la carrera de Procesos Industriales en el Área de Manufactura (PIAM), con el fin de obtener información que apoyara la planeación de las asignaturas en el cuatrimestre septiembrediciembre de 2012.

\section{Método}

Se eligió el manual de estilos de aprendizaje de Felder y Silverman (SEP, 2004) con base en la importancia teórica del modelo en el campo, su uso, y su influencia en la caracterización de otros estilos de aprendizaje, como son el de Kolb y el de los cuadrantes cerebrales de Hermann.

\section{Justificación}

Resulta útil determinar en los estudiantes el perfil del aprendizaje para adecuar las estrategias y orientar el aprendizaje de cada alumno por medio de estrategias didácticas específicas en una búsqueda para cumplir con el modelo centrado en el aprendizaje de la insti- 
tución. En lo que concierne a las carreras con enfoque de ingeniería, constituye una herramienta docente muy útil para adaptar el estilo de enseñanza del profesor y poder compartirlo con otros docentes que imparten asignaturas en la misma carrera. Así, permitirá diseñar métodos y técnicas de evaluación más apropiadas para comprobar el progreso de los estudiantes en el desarrollo de sus capacidades.

Para el alumno será de gran utilidad la información obtenida, ya que le permitirá planificar según sus propios estilos, encontrar estrategias que le permitan mejorar su propio aprendizaje, diagnosticar sus fortalezas y debilidades, describir su estilo de aprendizaje, lograr identificar plenamente cómo aprender mejor y superar las dificultades que se le presentan día a día en su proceso de formación.

En el grupo que se aplicó el modelo, se ha detectado a partir del intercambio de experiencias con otros profesores que los estudiantes muestran dificultad para comprender ciertos procedimientos que involucran lógica matemática, así como realizar prácticas de manera autónoma en plataformas educativas. Conocer los estilos de aprendizaje con un modelo como el que presentan Felder y Silverman permiti- rá contar con un registro documentado de los diferentes estilos de aprendizaje en un grupo determinado y focalizar las técnicas y estrategias de enseñanza-aprendizaje para lograr mejores resultados.

De acuerdo al modelo referido, se consideran cinco dimensiones de análisis: percibir (sensorial-intuitivo); recibir (visual-verbal); organizar (inductivo-deductivo); entender (secuencia-global), y procesar (activo-reflexivo). Una posterior versión suprime la dimensión de organización, que tiene que ver con lo inductivo y deductivo (Durán y Costaguta, 2007: 2).

A continuación, se hace una breve descripción de algunas de las categorías del modelo aplicado.

\section{Sensitivo/Intuitivo}

Está relacionada con el contenido concreto que presenta el profesor. Los alumnos sensitivos prefieren la explicación después de los ejemplos. Por su parte, los intuitivos prefieren descubrir posibilidades y relaciones, captan mejor los nuevos conceptos (Secretaría de Educación Pública, 2004).

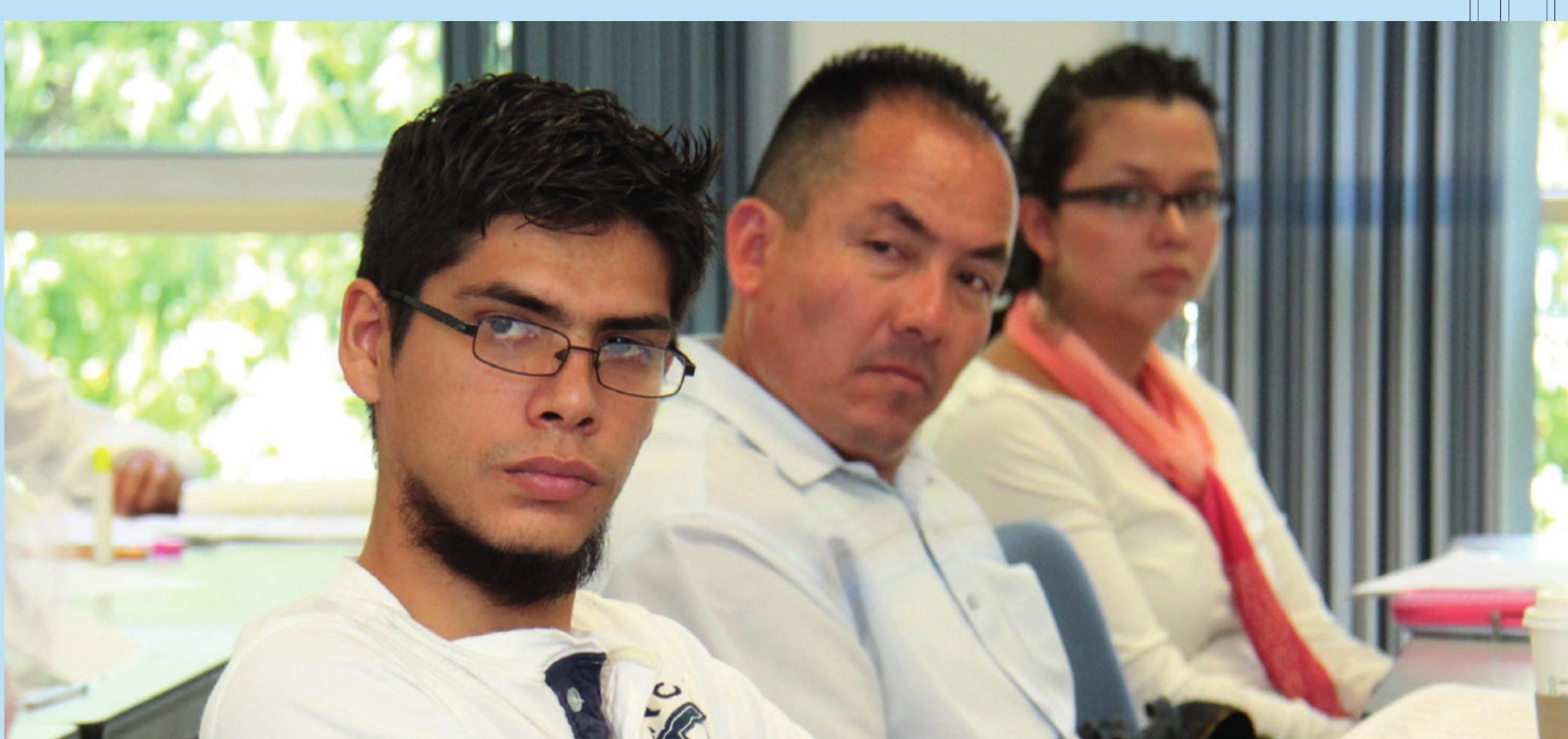


Visual/Verbal

Los alumnos visuales tienen la habilidad de percibir claramente el mundo que ven y lo recrean mediante recuerdos con imágenes y palabras, la inclusión en papel o en la mente; la instrucción para ellos podrá depender en gran medida de los requerimientos técnicos. Por su parte, los estudiantes verbales recuerdan más lo que escuchan y mucho más lo que ellos dicen y aprenden a partir de explicaciones verbales y discusiones. (SEP, 2004).

\section{Secuenciales/Globales}

Los alumnos secuenciales prefieren la instrucción que se aplica en la mayoría de la educación formal; dado que el material que se presenta tiene un orden lógico y secuencial prefieren llevar el curso en forma presencial. Por su parte, los estudiantes globales prefieren conducirse de manera más autónoma y autorregulada, son capaces de resolver problemas rápidamente después de captar el panorama general, pero tienen dificultad para explicar cómo lo hicieron.

\section{Activo/Reflexivo}

El procesamiento de información se puede dividir en dos grandes grupos: observación activa y observación reflexiva. La primera tiene que ver con el proceso de la información y aplicarla en un contexto real (discutirla, explicarla y compararla, de alguna manera). La segunda tiene que ver con el procesamiento de la información de manera cognitiva.

\section{Resultados y discusión}

Para realizar la interpretación se utilizó la siguiente escala: el puntaje que se encuentra entre 1-3 presenta equilibrio apropiado entre los dos extremos de esa escala. Si el puntaje está entre 5-7, presenta una preferencia moderada hacia uno de los dos extremos de la escala y aprenderá más fácilmente si le brindan apoyos en esa dirección. Si el puntaje del alumno se encuentra entre 9-11 presenta una preferencia muy fuerte por uno de los dos extremos de la escala.

Los resultados obtenidos con el test de Felder en el grupo de 17 alumnos se muestran en la gráfica y se describen a continuación:

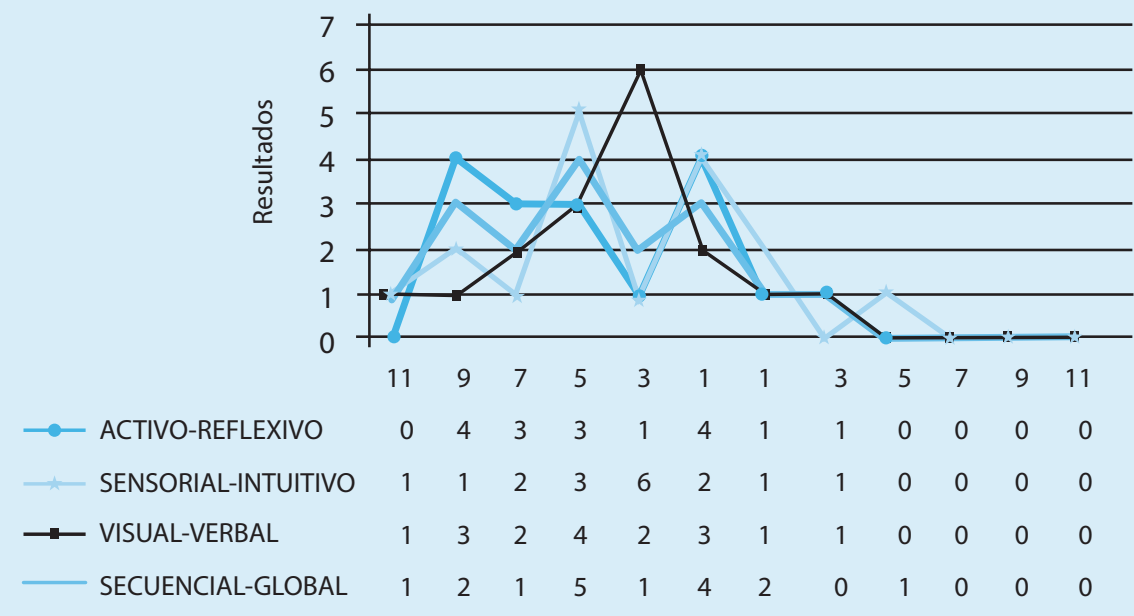


- En el perfil de activo-reflexivo, 7 de 17 alumnos tienen un equilibrio apropiado, 6 tienen una preferencia moderada, y 4 una preferencia muy fuerte a activos.

- En el perfil sensorial-intuitivo, 10 alumnos presentan un equilibrio apropiado, 5 presentan una preferencia moderada y 2 una preferencia muy fuerte hacia lo sensitivo.

- En el perfil visual-verbal, 7 alumnos presentan un equilibrio apropiado, 6 una preferencia moderada y 4 una preferencia muy fuerte hacia lo secuencial.

\section{Conclusión}

Este trabajo permitió determinar el estilo de aprendizaje de los alumnos utilizando el modelo Felder y Silverman con el propósito de utilizar esta información para correlacionarla con la planeación de las asignaturas que se impartirán en el siguiente ciclo escolar.

El profesor debe promover que su perfil profesional cuente con los recursos para tener una flexibilidad amplia en el diseño e impartición de las sesiones educativas, para lo cual resulta imprescindible el intercambio documentado de experiencia con otros docentes.
Los planes de formación de los profesores deben partir de un perfil de competencia que la institución debe elaborar y los cursos y talleres deben estar centrados en el desempeño y no sólo en el saber. Posteriormente, será necesario hacer un plan validación de los resultados y su seguimiento.

\section{Fuentes de consulta}

Delors, J. (1999). La educación encierra un tesoro. Informe a la UNESCO de la Comisión Internacional sobre Educación para el siglo XXI. París: Santillana Ediciones/UNESCO.

Durán, E. y Costaguta, R. (2007). Minería de datos para descubrir estilos de aprendizaje. (1. C. Organización de Estados Iberoamericanos para la Educación, Ed.) Recuperado el 30 de julio de 2012, de http://www.rieoei.org/ deloslectores/1674Duran.pdf.

Secretaría de Educación Pública (2004). Estilos de aprendizaje. México: Dirección de Coordinación Académica.

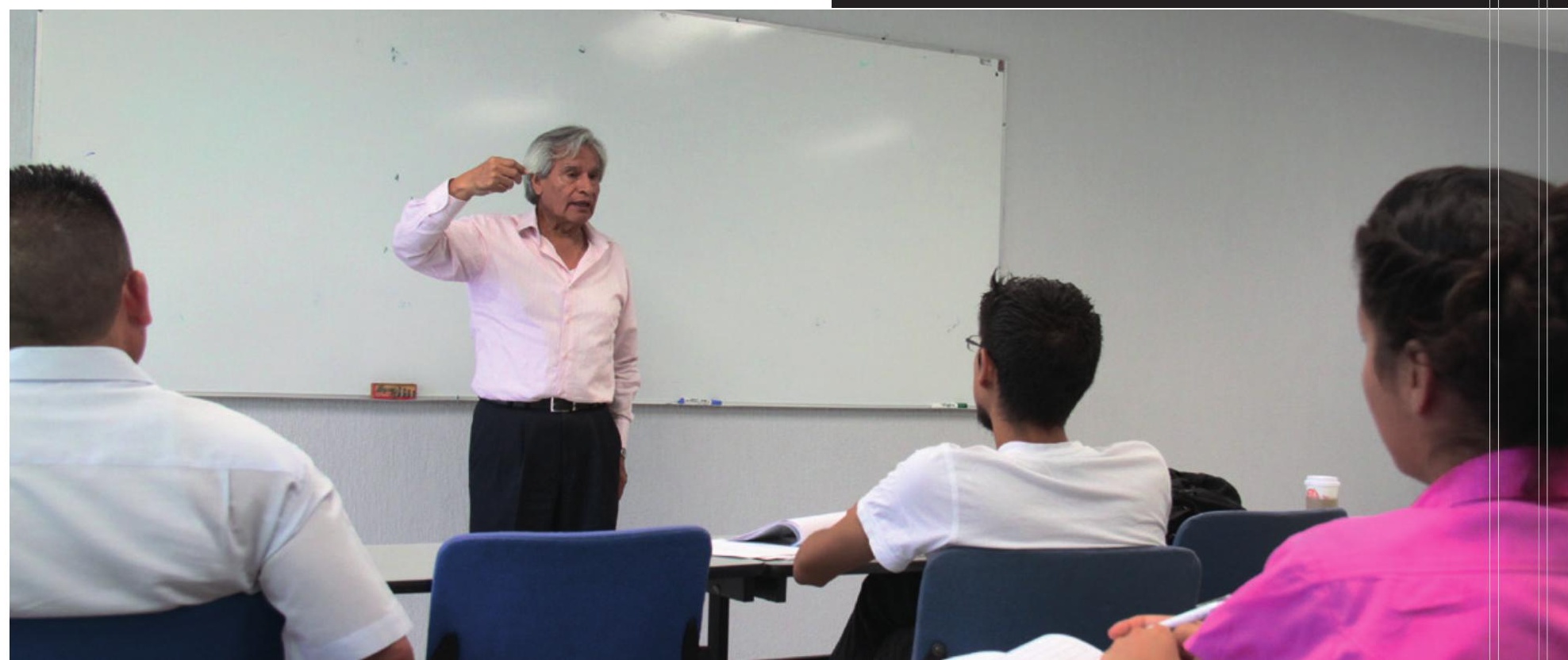

